\title{
BIO-EFFICACY ASSESSMENT OF SAGE, SALVIA OFFICINALIS L. EXTRACTS ON SOME BIOLOGICAL ASPECTS OF SPIDER MITE, TETRANYCHUS URTICAE KOCH (ACARI:TETRANYCHIDAE) \\ WAKED, DALIA A.
}

Plant Protection Research Institute, ARC, Dokki, Giza, Egypt

Email: dr.dalia188@yahoo.com

(Manuscript received 17 May 2016)

\begin{abstract}

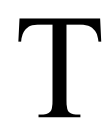
he usage of plant extracts for pest control is considered as an alternative control method to synthetic pesticides. The effect of methanol and water extracts obtained from Sage (Salvia officinalis L.) plant from the Lamiaceae family on Tetranychus urticae Koch was evaluated. The sprayed leaf disk method was used to determine the effect of the plant extracts. The effect of Sage extracts on the eggs and adult females was examined. Four concentrations of the plant extracts $5 \%, 10 \%$, $15 \%$ and $20 \%$ were evaluated. Mortality was observed after $1^{\text {st }}, 3^{\text {rd }}$ and $5^{\text {th }}$ days from treatment. The highest death rates of $T$. urticae adults were found at $20 \%$ concentration as $92.85 \%$ and $87.14 \%$ for methanol and water Sage extracts, respectively. Both extracts gave poor toxic effect to eggs compared with adult females. Both extracts proved superiority in repellency to spider mite, $T$. urticae. Rate of repellency was decreased gradually by time elapsed after treatment. T. urticae females preferred to settle, deposit eggs and feed on the untreated half of the disc and the majority refused to settle on the treated part especially with the high concentrations. Both solvent extracts shortened the longevity and reduced fecundity of adult females of $T$. urticae. As a consequence, Sage extracts are thought to be used as an alternative safe method for mite control.
\end{abstract}

Keywords: Sage, Salvia officinalis, Tetranychus urticae, Toxicity, Repellency.

\section{INTRODUCTION}

The two-spotted spider mite, Tetranychus urticae Koch (Acari: Tetranychidae) is one of the most serious agricultural pests in the world. This mite feeds by puncturing cells and draining the contents causing damage in chlorophyll producing white spots that may become more or less coherent with time Nachman and Zemek (2002). They also produce silk webbing which is clearly visible at high infestation levels. The importance of this mite pest is not only due to direct damage to plants but also decreases in photosynthesis and transpiration Brandenburg and Kennedy (1987). Studies of yield reduction caused by varying population levels of $T$. urticae have demonstrated its potential for damaging crops. Its outbreaksare often a consequence 
634 BIO-EFFICACY ASSESSMENT OF SAGE, SALVIA OFFICINALIS L. EXTRACTS ON SOME BIOLOGICAL ASPECTS OF SPIDER MITE, TETRANYCHUS URTICAE KOCH (ACARI:TETRANYCHIDAE)

of repeated and non-selective pesticide applications. The greatest problem with this mite is its ability to rapidly evolve resistance to pesticides Cranham and Helle (1985). In addition, the environmental problems caused by overuse of pesticides have been the matter of concern for both scientists and public in recent years. Therefore, alternative methods for controlling $T$. urticaeare needed. Natural products are an excellent alternative to synthetic pesticides as means to reduce negative impacts to human health and environment. Most of these products are environmentally non persistent and nontoxic to humans so far (with some exceptions) Hjorther et al. (1997). Some of the alternative control methods including plant essential oils, plant preparations and microbial secondary metabolites on the two-spotted spider mite are currently being researched (Calmasur et al. 2006 and Feng and Isman 1995). Plant compounds such as extracts were used as acaricids and, repellents (Venkatachalam and Jebanesan 2001 and Kumral et al. 2010) reported that methanolic extracts of Daturastramonium L. (Solanaceae) leaves and seeds exhibited acaricidal, oviposition deterrent activities against $T$. urticae. The Lamiaceae family is recognized for their vital oils, medicinal uses and antimicrobial activity of different species Skaltsa et al. (2003). A review of the chemical breakdown of species in this family has revealed a range of chemical components, predominantly mono and diterpenoids, of which a number possess a range of activities against numerous arthropods (Cole 1992 and Simmonds and Blaney 1992). Sage (Salvia officinalis) and Rosemary ( $R$. officinalis) belong to the Lamiaceae family are strong aromatic plants, which are predominantly used in conventional medicine, food and medicine industry because of their antioxidant and antimicrobial properties Biljana et al. (2007).Thus, the Objectives of this study were to assess the acaricidal activity of $S$. officinalis against $T$. urticae and to isolate active components.

\section{MATERIALS AND METHODS}

\section{Rearing of spider mite, Tetranychus urticae Koch}

Field samples of bean plant (Phaseoulus vulgaris L.) leaves infested with spider mite, $T$. urticae were collected and transferred to the laboratory. The culture was initiated by transferring female and male individuals to leaves of mulberry, Morus alba L. placed on cotton wool pad, fully saturated with water as a source of moisture and to prevent mite from escaping. Old leaves were changed as necessary. Females were transferred to clean leaves, allowed to oviposit for $24 \mathrm{hr}$., then removed. Development of these eggs resulted in a cohort of evenly aged mites that were used for all 
bioassays. The colony was kept under controlled conditions in the laboratory $\left(28 \pm 2{ }^{\circ} \mathrm{C}\right.$ and $65 \pm 5 \%$ R.H).

\section{Preparation of Salvia officinalis extracts}

Salvia officinalis leaves were collected during the vegetation period from production areas of El-Arish district. Plant material was dried under shade, powdered by using an electric grinder, and kept in the dark at room temperature in 3 liters glass jars until it was used. The extraction procedure used in the study was described by Gokçe et al. (2005) where plant extract was prepared from a representative sample of $100 \mathrm{~g}$ of powdered plant material taken into a 2 liters capacity Erlenmeyer flask for each solvent, methanol and water. $300 \mathrm{ml}$ of each solvent were added and shaken for $24 \mathrm{hr}$. in a horizontal shaker at $120 \mathrm{rpm}$ at room temperature. The plant suspension was sieved through four layers of cheese cloths to separate plant parts. Extract was transferred into a $250 \mathrm{ml}$ evaporating flask and evaporated under a vacuum using a rotary vacuum evaporator at $32^{\circ} \mathrm{C}$. The extract solutions were kept in a refrigerator at $4^{\circ} \mathrm{C}$ until they were used in the bioassay.

\section{Gas chromatography-mass spectrometry analysis (GC/MS)}

Volatile compound analysis was performed with a gas chromatography system (Agilent $6890 \mathrm{GC}$ ) with an Agilent mass spectrometric detector, with a direct capillary interface and fused silica capillary column PAS-5 MS (30 m $\times 0.32 \mathrm{~mm} \times 0.25 \mu \mathrm{m}$ film thickness). Helium was used as the carrier gas at a flow about $1.0 \mathrm{ml} / \mathrm{min}$ pulsed splitless. The solvent delay was $3 \mathrm{~min}$. and the injection size was $1.0 \mu \mathrm{l}$. The mass spectrometric detector was operated in an electron impact ionization mode with an ionizing energy of $70 \mathrm{eV}$. Scanning from $\mathrm{m} / \mathrm{z} 50$ to 500 and the ion source temperature was $230^{\circ} \mathrm{C}$. The electron multiplier voltage (EM voltage) was maintained $1250 \mathrm{v}$ above auto tune. The instrument was manually turned using perfluorotributyl amine (PFTBA). Oven temperature program at $45^{\circ} \mathrm{C}(2 \mathrm{~min}), 150^{\circ} \mathrm{C}(5 \mathrm{~min})$ at a rate of $2^{\circ} \mathrm{C}$ min- 1 , then at $150^{\circ} \mathrm{C}(2 \mathrm{~min}), 280^{\circ} \mathrm{C}(5 \mathrm{~min})$ at a rate of $8^{\circ} \mathrm{C}$ min- 1 ; split 30:1 during 1.50min, carrier gas He: $1 \mathrm{ml} \mathrm{min-1}$, constant flow; sample volume $1 \mu \mathrm{l}$. To identify the parts was based on comparison of their mass spectra with those of Wiley and Nist Tutore Libraries Adams (1995).

\section{Toxicity of Salvia officinalis extracts to spider mite, T. urticae eggs}

Mated mite females were transferred to four leaf discs ( 15 females each) about (each of $2.4 \mathrm{~cm}$ in diameter) which were placed in 4 prepared Petri- dishes on moist cotton to prevent desiccation of leaf. They were allowed to lay eggs on the lower surface of mulberry leaves, for $24 \mathrm{hr}$. The adult females were removed after $24 \mathrm{hr}$. 
636 BIO-EFFICACY ASSESSMENT OF SAGE, SALVIA OFFICINALIS L. EXTRACTS ON SOME

BIOLOGICAL ASPECTS OF SPIDER MITE, TETRANYCHUS URTICAE KOCH (ACARI:TETRANYCHIDAE)

and the number of deposited eggs per disc was counted and recorded about 80 eggs for each concentration (20,15, 10 and 5\%). The disc surface carrying the eggs was gently dipped separately in concentrations from each extract solvents for about 5 seconds. In control test, the leaf discs were dipped in distilled water only. The treated and untreated eggs were kept under constant temperature of $28 \pm 2^{\circ} \mathrm{C}$ and $65 \pm 5 \%$ R.H., In all cases, hatchability percentages and incubation period were assessed.

\section{Toxicity of Salvia officinalis extracts to spider mite, $T$. urticae females}

The leaf spray method was applied to test the efficacy of the two extracts separately. Each extract was tested with different concentrations (20,15, 10 and 5 $\%) . \mathrm{LC}_{50 \mathrm{~s}}$ from each extract was determined. Total number of 80 individuals (females) as the same age was bio-assayed in 8 replicates of 10 adult females each. Petri-dishes having the same number of females were sprayed with water and used as a control. All discs were placed on moist cotton wool pad in Petri-dishes (9 $\mathrm{cm}$ in diameter). Discs were sprayed with tested concentrations using a manual atomizer. The treated females and untreated ones were kept under the same conditions of $28 \pm 2^{\circ} \mathrm{C}$ and relative humidity of $65 \pm 5 \%$ R.H. Mortality percentage was calculated1, 3 , and 5 days after treatment.

\section{Repellency effect of Salvia officinalis extracts against spider mite, T. urtiae females}

To study the repellency effect of Sage extracts against females of spider mite, T. urtiae at different concentrations $(20,15,10$ and $5 \%)$ of each extract were used. Mulberry leaves were cleaned and cutted into two parts of symmetrical portion along the midrib. One leaf portion of the disc was dipped in tested concentration of each extracts where the other half was dipped in water (control). The treated discs were left to dry and put on top of a wetted filter paper placed inside glass Petri-dishes (10 $\mathrm{cm}$ in diameter). Eighty $T$. urticae females were distributed on eight discs and used as replicates of 10 adult females of $T$. urticae each and placed in the middle between the two leaf portions. The number of mites found on each leaf portion was counted after 1, 2, 3 and 4 days from exposure. The repellency percentages were computed.

\section{Statistical analysis}

Data were subjected to statistical analysis using one way analysis of variance, ANOVA Duncan(1955). 


\section{RESULTS AND DISCUSSION}

\section{Chemical composition of Salvia officinalis leaves}

The bioactive phytochemicals of $S$. officinalis leaves were analyzed by using hydrodistillation and GC-MS. The results revealed 24 compounds representing $99.42 \%$ of the contents Table (1).The identification of phytochemical compounds is based on the peak content (1S,4R,5R) 4-Methyl-1-(propan-2-yl)bicycle[3.1.0] hexan-3-onehas peak content $29.90 \%$ with RT15.11 min. followed by 1,7,7-Trimethyl bicyclo [2.2.1] heptan2-one, (1S,4S,5R)-4-methyl-1-propan-2-yl bicyclo[3.1.0]hexan-3-oneand 1,3,3Trimethyl-2-oxabicyclo [2,2,2] octane have $16.74 \%, 13.68 \%$ and $12.31 \%$ with RT $17.20 \mathrm{~min}, 15.30 \mathrm{~min}$. and $12.20 \mathrm{~min}$. , respectively.

Table 1. Compositions and percentages of volatiles from $S$. Officinalis leaves

\begin{tabular}{|l|l|c|c|}
\hline No. & \multicolumn{1}{|c|}{ Compound name } & RT/min. & Content\% \\
\hline 1 & (1S,5S)-2,6,6-Trimethylbicyclo [3.1.1] hept-2-ene & 9.21 & 2.78 \\
\hline 2 & 6,6-Dimethyl-2-methylenebicyclo [3.1.1] heptane & 10.93 & 1.18 \\
\hline 3 & 2,2-Dimethyl-3-methylene-bicyclo [2.2.1] heptane & 11.04 & 3.04 \\
\hline 4 & 7-Methyl-3-methylene-1,6-octadiene & 11.66 & 0.34 \\
\hline 5 & 1,3,3-Trimethyl-2-oxabicyclo [2,2,2] octane & 12.20 & 12.31 \\
\hline 6 & 1-Methyl-4-(1-methylethenyl)-cyclohexene & 13.70 & 0.43 \\
\hline 7 & 1-Isopropyl-2-methylbenzene & 14.08 & 0.58 \\
\hline 8 & 3,7-Dimethylocta-1,6-dien-3-ol & 14.50 & 1.38 \\
\hline 9 & (1S,4R,5R) 4-Methyl-1-(propan-2-yl)bicycle[3.1.0] hexan-3-one & 15.11 & 29.90 \\
\hline 10 & (1S,4S,5R)-4-methyl-1-propan-2-ylbicyclo[3.1.0]hexan-3-one & 15.30 & 13.68 \\
\hline 11 & (2S,5R)-2-Isopropyl-5-methyl cyclo hexanone & 16.21 & 0.93 \\
\hline 12 & 1,7,7-Trimethylbicyclo [2.2.1] heptan-2-one & 17.20 & 16.74 \\
\hline 13 & (1R,2S,5R)-2-Isopropyl-5-mmethyl cyclohexanol & 18.20 & 1.63 \\
\hline 14 & Endo-1,7,7-Trimethyl-bicyclo [2.2.1] heptan-2-ol & 20.32 & 1.8 \\
\hline 15 & 2-(4-methyl-1-cyclohex-3-enyl) propan-2-ol & 21.24 & 0.04 \\
\hline 16 & 2-methyl-5-(1-methylethenyl)-2-cyclohexenone & 22.20 & 0.71 \\
\hline 17 & 3,7-dimethylocta-1,6-dien-3-yl acetate & 23.10 & 0.45 \\
\hline 18 & (trans)-3,7-dimethyl-2,6-octadien-1-ol & 23.48 & 0.21 \\
\hline 19 & (1S,2R,4S)-1,7,7-Trimethyl bicyclo [2.2.1] hept-2-yl acetate & 24.15 & 2.23 \\
\hline 20 & 2-Isopropyl-5-methyl phenol & 25.00 & 1.91 \\
\hline 21 & 2,6,6,9-Tetramethyl-1,4-8-cycloundecatriene & 26.18 & 2.41 \\
\hline 22 & (2E,6E)-3,7,11-Trimethyldodeca-2,6,10-trien-1-ol & 27.12 & 0.61 \\
\hline 23 & 5-Isopropyl-2-methyl phenol & 28.23 & 3.32 \\
\hline 24 & 2,3,4,9,10,10a-hexahydrophenanthrene-4a-carboxylic acid & 0.81 \\
\hline
\end{tabular}

RT: Retention Time 


\section{Toxicity of Salvia officinalis against eggs and adult females of spider mite,}

\section{T. urticae.}

The results showed that the ovicidal action of the experimented natural extract against eggs of $T$. urticae varied considerably Table (2). Both extracts were effective on eggs and caused unhatchability. $20 \%$ concentration caused $35 \%$ and 25 $\%$ for methanol and water extracts while, $5 \%$ concentration was the lowest one that caused $22.5 \%$ and $18.75 \%$ for the same previous order, respectively. In addition to increasing the incubation period to 5.32 days compared with control of 3.47 days. These results are agreement with Hussein et al. (2006) who stated that ethyl acetate extract of the plant Capparis aegyptia leaves and fruits were the most potent extracts tested against $T$. urticae egg Barakat et al. (1984) tested some plant extracts against adults and eggs of $T$. urticae. Eggs were less affected than adults, but extracts of Piper nigrum and Datura stramonium showed considerable ovicidal properties.

Mortality percentages of females increased with increasing the concentrations of both solvents extracts. Methanol extract was more effective extract against females that caused $92.85 \%$ mortality 5 days after treatment at $20 \%$ concentration compared with water extract $87.14 \%$ mortality at the same concentration. However, each of $10 \%$ and $15 \%$ concentrations caused variable mortality percentages ranged from $70 \%$ to $84.29 \%$. The lowest concentration caused $57.14 \%$ and $65.71 \%$ mortality for water and methanol extracts, respectively. These results agree with Saber and Isman (2006) who assessed the efficacy of rosemary, Rosmarinus officinalis L., essential oil against the two-spotted spider mite. Laboratory bioassay results indicated that pure rosemary oil caused complete mortality of spider mite at concentrations that aren't phytotoxic to the host plant.

Table 2. Effect of the Sage extracts against eggs and adult females of T. urticae

\begin{tabular}{|c|c|c|c|c|c|c|}
\hline \multirow{2}{*}{$\begin{array}{c}\text { Concentrations } \\
\text { A. I.\% }\end{array}$} & \multirow{2}{*}{ Solvents } & Unhatchability \% & $\begin{array}{c}\text { Incubation } \\
\text { period (days) }\end{array}$ & 1 day & 3 days & $\begin{array}{c}5 \\
\text { days }\end{array}$ \\
\cline { 3 - 7 } & & $22.5^{\mathrm{c}}$ & $4.09 \pm 0.04$ & 14.28 & 27.4 & $65.71^{\mathrm{e}}$ \\
\hline \multirow{2}{*}{$5 \%$} & Methanol & $18.75^{\mathrm{d}}$ & $3.52 \pm 0.02$ & 10.00 & 18.57 & $57.14^{\mathrm{f}}$ \\
\cline { 2 - 7 } & Water & $27.5^{\mathrm{b}}$ & $4.58 \pm 0.05$ & 22.85 & 51.42 & $78.57^{\mathrm{c}}$ \\
\hline \multirow{2}{*}{$10 \%$} & Methanol & $21.25^{\mathrm{c}}$ & $3.95 \pm 0.12$ & 17.14 & 42.85 & $70.00^{\mathrm{d}}$ \\
\cline { 2 - 7 } & Water & $33.75^{\mathrm{a}}$ & $5.03 \pm 0.03$ & 34.85 & 64.28 & $84.29^{\mathrm{b}}$ \\
\hline \multirow{2}{*}{$15 \%$} & Methanol & $22.5^{\mathrm{c}}$ & $4.24 \pm 0.06$ & 28.57 & 52.85 & $71.42^{\mathrm{d}}$ \\
\hline \multirow{2}{*}{$20 \%$} & Water & $35.00^{\mathrm{a}}$ & $5.32 \pm 0.04$ & 44.28 & 77.14 & $92.85^{\mathrm{a}}$ \\
\hline & Methanol & $25.00^{\mathrm{b}}$ & $4.66 \pm 0.01$ & 31.42 & 72.85 & $87.14^{\mathrm{ab}}$ \\
\hline & Water & 0 & $3.47 \pm 0.02$ & 0 & 2.85 & 4.28 \\
\hline
\end{tabular}

Means in the columns followed by the same letter are not significantly different at $5 \%$ level (Duncan's multiple range tests). \pm Standard Error 
Mwandila et al. (2013) evaluated the effect of Syringa (Melia azedarach) fruit and seed extracts (SSE) on red spider mite (Tetranychus spp.) eggs, nymphs and adults which it was high toxic and raised the mortality percentage to $90 \%$ two days after treatment.

\section{Repellency effect of Salvia officinalis extracts on T. urticae females.}

Data in Table (3) showed that four levels of concentrations (5, 10, 15 and $20 \%$ ) for methanol and water extracts were tested for repulsion percentages of $T$. urticae. The repellency effect reached an average of $81.25 \%$ at $20 \%$ concentration of methanol extract one day after application and that considered the most effective one. The rate of repellency effects were decreased gradually by time elapsed after treatment, which was pronounced with all the tested extracts ranged between $81.25 \%-16.25 \%$ and $73.75 \%-12.50 \%$ one day and four days after treatment for methanol and water extract, respectively. Each of $10 \%$ and $15 \%$ concentrations were succeeded in repulsion $T$. urticae individuals, where the repellency reached $50 \%$. At $5 \%$ concentration, the repellency effect dropped from $33.75 \%$ to $3.75 \%$ and from $38.75 \%$ to $6.25 \%$ for methanol and water extracts four days after application, respectively. These findings indicated that when concentration increased the repellency percent also increased. The female mites may control eating when food is abundant. However, under food shortage the mites feed in other areas to guarantee their survival. These results are in agreement with Saber (2004)who tested the effect of petroleum ether, chloroform, ethyl acetate and ethanol extracts of sand wormwood (Artemisia monosperma) against $T$. urticae females. The majority of mite females preferred settle and feeding on untreated discs, while few individuals fed on the treated portions.

Table 3. Repellency effect of Sage extracts against $T$. urticae

\begin{tabular}{|c|c|c|c|c|c|}
\hline \multirow{2}{*}{$\begin{array}{c}\text { Concentrations } \\
\text { A. I. } \%\end{array}$} & \multirow{2}{*}{ Solvents } & \multicolumn{4}{|c|}{ Repellency\% / days after treatment } \\
\cline { 3 - 6 } & & 1 & 2 & 3 & 4 \\
\hline \multirow{2}{*}{20} & Methanol & $81.25^{\mathrm{a}}$ & 65.00 & 36.25 & $16.25^{\mathrm{a}}$ \\
\cline { 2 - 6 } & Water & $73.75^{\mathrm{b}}$ & 60.00 & 40.00 & $12.50^{\mathrm{b}}$ \\
\hline \multirow{2}{*}{15} & Methanol & $71.25^{\mathrm{b}}$ & 60.00 & 30.00 & $11.25^{\mathrm{b}}$ \\
\cline { 2 - 6 } & Water & $62.5^{\mathrm{c}}$ & 50.00 & 33.75 & $8.75^{\mathrm{c}}$ \\
\hline \multirow{2}{*}{10} & Methanol & $56.25^{\mathrm{d}}$ & 45.00 & 23.75 & $6.25^{\mathrm{c}}$ \\
\cline { 2 - 6 } & Water & $50^{\mathrm{d}}$ & 38.75 & 21.25 & $7.50^{\mathrm{c}}$ \\
\hline \multirow{2}{*}{5} & Methanol & $33.75^{\mathrm{e}}$ & 25.00 & 16.25 & $3.75^{\mathrm{d}}$ \\
\cline { 2 - 6 } & Water & $38.75^{\mathrm{e}}$ & 27.50 & 18.75 & $6.25^{\mathrm{c}}$ \\
\hline
\end{tabular}

Means in columns followed by the same letter are not significantly different at $5 \%$ level (Duncan's multiple range tests) 
640 BIO-EFFICACY ASSESSMENT OF SAGE, SALVIA OFFICINALIS L. EXTRACTS ON SOME

BIOLOGICAL ASPECTS OF SPIDER MITE, TETRANYCHUS URTICAE KOCH (ACARI:TETRANYCHIDAE)

The petroleum ether extract was the most effective in repellency effect $99.76 \%$. Dhroug, et al. (2000) indicated that Bitter apple seed hexane extract proved superiority in repellency effect against spider mites followed by camphor / olive oil mixture. They added that the crude American aloe juice and crude banana leaves juice gave inefficiency effect for mite.

\section{Latent effect of $\mathbf{L C}_{50}$ of Salvia officinalis extractson longevity and fecundity of $T$. urticea females.}

Data in Table (4) showed that all solvents extracts shortened the longevity and reduced fecundity of $T$. urticae. Pre-oviposition period lasted 2.13 and 1.98 days for methanol and water extract as compared with 1.82 days for untreated one, respectively. On the other hand, oviposition period was 13.75 and 16.07 days for the same solvents while it was 2.44 and 2.51 days for post-oviposition while it was 2.9 days for untreated one, respectively. So, longevity averaged 18.32 and 20.56 days for methanol and water extract and 23.93 days for control, respectively. The total number of deposited eggs for methanol and water extract were (31.39 and 38.92 eggs) while it was (65.31 eggs) for untreated females. These results similar to those of Kawka and Tomczyk (2002)who evaluated both extracts made of fresh and dry leaves of $S$. officinalis that reduced the total number of eggs produced by $T$. urticae females by about $35-45 \%$. The female longevity was reduced by about $25 \%$. Activity of females feeding on ivy leaves was strongly affected by Sage extracts.

Table 4. Latent effect of $\mathrm{LC}_{50 \mathrm{~s}}$ different Sage extracts on $T$. urticae female biology

\begin{tabular}{|l|c|c|c|c|c|}
\hline Extracts & $\begin{array}{c}\text { Pre-oviposition } \\
\text { period }\end{array}$ & $\begin{array}{c}\text { Oviposition } \\
\text { period }\end{array}$ & $\begin{array}{c}\text { Post-oviposition } \\
\text { period }\end{array}$ & $\begin{array}{c}\text { Longevity } \\
\text { days }\end{array}$ & Fecundity \\
\hline Methanol & $2.13 \pm 0.36$ & $13.75 \pm 1.14$ & $2.44 \pm 0.54$ & $18.32 \pm 2.04^{\mathrm{b}}$ & $31.39 \pm 3.12^{\mathrm{c}}$ \\
\hline Water & $1.98 \pm 0.12$ & $16.07 \pm 2.07$ & $2.51 \pm 0.26$ & $20.56 \pm 2.35^{\mathrm{b}}$ & $38.92 \pm 3.95^{\mathrm{b}}$ \\
\hline Control & $1.82 \pm 0.09$ & $19.21 \pm 2.11$ & $2.90 \pm 0.18$ & $23.93 \pm 3.18^{\mathrm{a}}$ & $65.31 \pm 4.68^{\mathrm{a}}$ \\
\hline
\end{tabular}

Means in columns followed by the same letter are not significantly different at $5 \%$ level (Duncan's multiple range tests). \pm Standard Error

Generally, it was found that Sage plant methanol extract showed an obvious effect on T. urticae eggs and adults under laboratory conditions. Synthetic pesticides, which are widely used, are known for causing adverse effects on human beings, the environment, and other creatures. It is considered that some components involved in the Sage extracts show contact effect as well as different effects such as preventing feeding of T. urticae. This agrees with Badawy et al. (2010) who reported that monoterpenes such as 1,8-cineole, limonene and carvone have a strong fumigant activity against $T$. urticae. Hori and Komatsu (1997) also found that the 1,8-cineole 
and camphor components of Sage and Rosemary had repellency effect on $T$. urticae adults and nymphs. Pesticidal efficiency was proved against $T$. urticae that decreased the ovipisition period and the number of deposited eggs Bakr, (2013). Ebadollahi et al. (2014) studied the effect of essential oils from fennel, Foeniculum vulgare Mill and lavender, Lavandula angustifolia Miller against adult females of T. urticae and chemical composition of these oils was analyzed by GC-MS, Anethole, limonene, $\alpha$ fenchone, linalool, 1,8-cineole and 1- borneol that affected on T. urticae with contact and fumigant toxicity. However, it is necessary to perform experiments of Sage plant extract under field conditions and compare them with the laboratory treatments. In addition, it is believed that performing different types of research by determining the effects of this plant extract on natural enemies would be helpful.

\section{REFERENCES}

1. Adams, R. 1995. Identification of essential oil components by Gas Chromatography/Mass Spectroscopy. Allured Publishing Co., Carol Stream, IL.

2. Badawy, M. E. L.; S. A. A. El-Arami, and S. A. M. Abdelgaleil. 2010. Acaricidal and quantitative structure activity relationship of monoterpenes against the twospotted spider mite, Tetranychus urticae. Exp. Appl. Acarol., 52: 261-274.

3. Bakr, E. M. 2013. Fumigant toxicity of camphor against Tetranychus urticae Koch and two phytoseid predators (Tetranychidae:Phytoseiidae). Acarines, 7(2):53-56

4. Barakat, A. A.; G. M. Shereef; S. A. Abdallah and S. A. A. Amer. 1984. Toxic action of some plant extracts against Tetranychu surticaeKoch. Bull. Soc. Ent. Egypt, 14: $233-242$.

5. Biljana, B;N. D. Mimica;I. Samojlik and E. Jovin. 2007. Antimicrobial and antioxidant properties of rosemary and sage (Rosmarinus officinalisL. and Salvia officinalis L., Lamiaceae) essential oils.J. Agricul. Food Chemist. 55: 7879- 7885

6. Brandenburg, R. L. andG. G. Kennedy. 1987. Ecological and agricultural considerations in the management of two-spotted spider mite (Tetranychu surticae Koch). Agric. Zool. Reviews 2: 185-236.

7. Calmasur, Ö;İ. Aslan and F. Sahin. 2006. Insecticidal and acaraicidal effect of three Lamiaceae plant essential oils against Tetranychus urticae Koch and Bemisi atabaci Genn. Industry. Crops \& Products 23: 140-146

8. Cole, M. D. 1992. The signifcance of the terpenoids in the Labiatae. In R. M Harley \& T Reynolds (eds.), Advances in Labiatae science, United Kingdom. 315324 
642 BIO-EFFICACY ASSESSMENT OF SAGE, SALVIA OFFICINALIS L. EXTRACTS ON SOME BIOLOGICAL ASPECTS OF SPIDER MITE, TETRANYCHUS URTICAE KOCH (ACARI:TETRANYCHIDAE)

9. Cranham, J. E. andW. Helle. 1985. Pesticide resistance in Tetranychidae in World crop pests spider mites: their natural enemies and control. Elsevier, Amsterdam, the Netherlands. 405-421

10. Dahroug, S. M.; A. K. Sobeiha; A. M. J. Farragg and E. M. Bakr. 2000. Repellency effect of certain botanical extracts against the red spider mite and black bean aphid. Annals of Agric. Sc. Moshtohor, 38(4):2543-2550

11. Duncan, D. B. 1955. Multiple range and multiple F. tests. Biometrics. 11:1- 41

12. Ebadollahi, A.; J. J.Sendi; A. Aliakbar and J. Razmjou. 2014. Chemical composition and acaricidal effects of essential oils of Foeniculum vulgare Mill. (Apiales: Apiaceae) and Lavandula angustifolia Miller (Lamiales: Lamiaceae) against Tetranychus urticae Koch (Acari: Tetranychidae). Hindawi Publishing Co., Psyche. 1-6

13. Feng, R. and M. B. Isman. 1995. Selection for resistance to azadirachtin in the green peach aphid, Myzus persicae Experiantia 51: 831-833

14. Gokce, A.; L. L. Stelenski and M. E. Whalon. 2005. Behavioral and electrophysiological responses of leafroller moths to selected plant extracts. Environ. Entomol. 34:1426-1432.

15. Hjorther, A. B. C.;B. Christophersen;M. Hausen;T. Menne. 1997. Occupational allergic contact dermatitis from carnosol, a naturally-occurring compound present in rosemary. Contact Dermatitis 37: 99-100

16. Hori, M. and H. Komatsu. 1997. Repellency of rosemary oil and its components against the onion aphid, Neotoxoptera formosana (Takahashi) (Homoptera: Aphididae). Appl. Entomol. Zool., 32: 303-310.

17. Hussein, H.; M. Abou El-Ella; S.A.A. Amer and F.M. Momen. 2006. Repellency and toxicity of extracts from Capparisa egyptia L. to Tetranychus urticae Koch. (Acari: Teranychidae). Acta, Phytopathologica, Entomologica, Hungarica., 41: 331- 340

18. Kawka B. and A. Tomczyk. 2002. Influence of extract from sage (Salvia officinalis L.) on some biological parameters of Tetranychus urticae Koch. Feeding on Algerian Ivy (Hedera helix variegate L.). Bulletin OILB/SROP 22(1): 96-100

19. Koul, O.; S. Walia andG. S. Dhaliwal. 2008. Essential oils as green pesticides: Potential and Constraints. Biopesticides International 4(1): 63-84

20. Kumral, N. A.; S. Çobanoglu and C. Yalçın. 2010. Acaricidal, repellent and oviposition deterrent activities of Datura stramonium L. against adult Tetranychus urticae (Koch) . J. Pest Science83: 173-180

21. Mwandila, N. J. K.; J. Olivier; D. Munthali and D. Visser. 2013. Efficacy of Syringa (MeliaAzedarach L.) extracts on eggs, nymphs and adult red spider mites, 
Tetranychus spp. (Acari: Tetranychidae) on tomatoes. African J. Agric. Res. 8(8): 695-700

22. Nachman, G. and R. Zemek. 2002. Interactions in a tritrophic acarine predatorprey metapopulation system III: Effects of Tetranychu surticae (Acari: Tetranychidae) on host plant condition. Exp. Appl. Acarol. 25: 27-42.

23. Perrucci, S.; G. Macchioni; P. L. Gioni; G. Flamini and I. Morelli. 1995. Structure toxicity relationship of some natural monoterpenes as acaricides against Psoroptescuniculi. J. Natural Products 58:1216-1264.

24. Saber, S.A. 2004. Influence of Artemisia monosperma Del, extracts on repellency, ovipositon deterrence and biological aspects of the two spotted spider mite, Tetranychus urticae Koch. Egyptian, J. Biological, pest, Control. 14 (2): 345 348.

25. Saber, M. and M. B. Isman. 2006. Efficacy and persistence of Rosemary oil as an acaricide against two spotted spider mite (Acari: Tetranychidae) on greenhouse. J. Econ. Entomol., 99(6): 2015-2023

26. Simmonds, M. S. J. and W. M. Blaney. 1992. Labiatae-insect interactions: effects of Labiatae-derived compounds on insect behaviour. In R M Harley \& T Reynolds (Eds.), Advances in Labiate science. Royal Botanic Gardens Kew, United Kingdom. 375-392

27. Skaltsa, H.; C. Demetzos; C.LazariandT. Sokovi. 2003. Essential oil analysis and antimicrobial activity of eight Stachys species from Greece. Phytochemistry. 64: 743-752

28. Venkatachalam, M. R. and A. Jebanesan. 2001. Repellent activity of Ferronia elephantum Corr. (Rutaceae) leaf extract against Aedesa egypti (L.). Bioresource Technology 76: 287-288. 
تقييم الكفاعة الحيوية لمستخلص المرمرية . Salvia officinalis L. على بعض

\title{
الظواهر الحيوية للحلم العنكبوتى Tetranychus urticae Koch (Acari:Tetranychidae )
}

\author{
داليا عبدالرحمن أحمد واكد \\ معهد بحوث وقاية النباتات - مركز البحوث الزراعية -الدقى-الجبزة-مصر
}

تعتبر المستخلصات النباتية أحد البدائل الآمنه بيئياً فى مكافحة بعض الآفات الثاقبة الماصة

ويعتبر العنكبوت الأحمر العادى أحد هذه الآفات الهامه الذى يصيب معظم المحاصيل الحقلية لئية

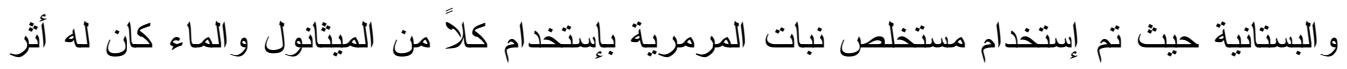

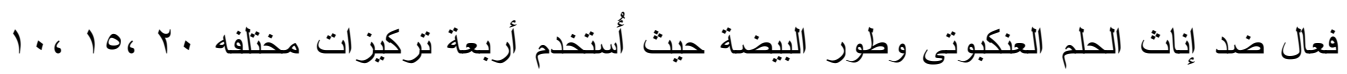

و و \% من مستخلص المرمرية وتم حساب نسبة الموت بعد ا ، ب و و يوم من المعاملة.

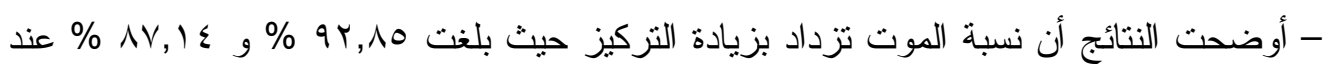

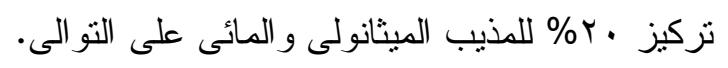

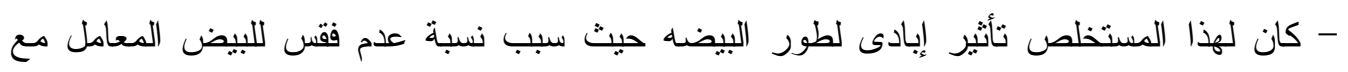

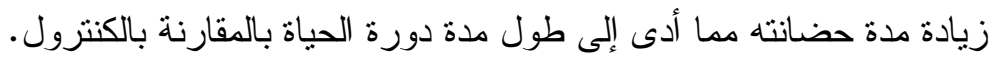

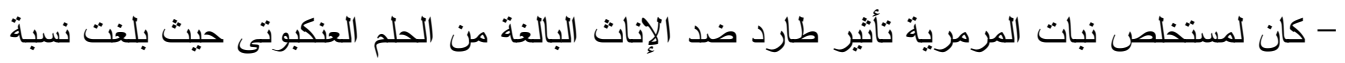

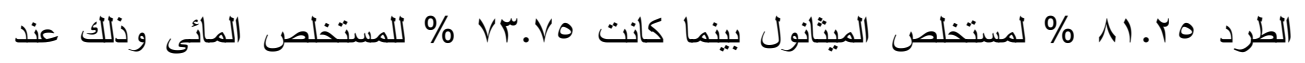

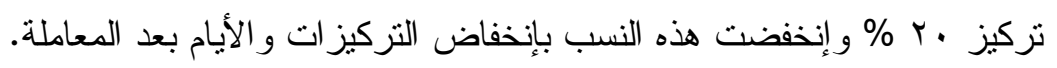

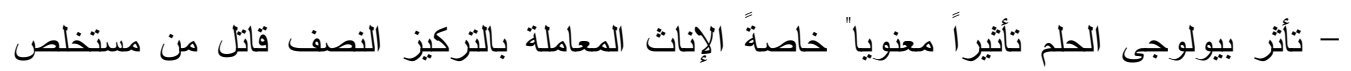

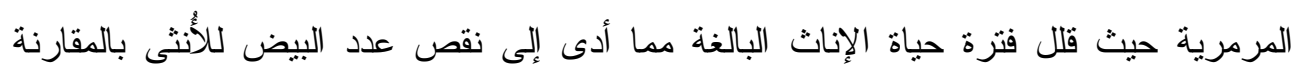
بالكنتزول. 